\title{
ENDOPHYTE INFECTION INFLUENCES DISAPPEARANCE OF PERENNIAL RYEGRASS SEED
}

\author{
A. POPAY, S. MARSHALL and J. BALTUS \\ AgResearch, Ruakura Research Centre, Private Bag 3123, Hamilton
}

\begin{abstract}
Disappearance of endophyte-free perennial ryegrass seed placed on bare ground was compared with that of seed infected by the fungal endophyte, Neotyphodium lolii, in four field trials. One trial included clover seed and two trials contained seed infected with two different endophytes. Infection with either endophyte significantly reduced seed disappearance and increased survival of seed to germination. Clover seed disappeared at a similar rate to endophyte-free ryegrass seed. Bird netting reduced seed disappearance of all treatments but in most cases not significantly so. Feeding by black field cricket nymphs and adults, small field cricket adults and black beetle adults on ungerminated and newly germinated endophyte-infected and endophyte-free seed was tested in the laboratory. It was concluded that none of these insects caused the differences in seed disappearance observed in the field.

Keywords: seed, perennial ryegrass, Neotyphodium, insects.
\end{abstract}

\section{INTRODUCTION}

The fungal endophyte Neotyphodium lolii, which infects perennial ryegrass (Lolium perenne) is maternally transmitted through the seed and can therefore be naturally perpetuated in pasture. The endophyte confers on its host plant resistance to certain insect pests, principally Argentine stem weevil, Listronotus bonariensis (Prestidge et al. 1982), and black beetle (Heteronychus arator) (Ball and Prestidge 1992), so giving it a selective advantage in the pasture system. As a result, new pastures sown to endophyte-free ryegrass in New Zealand often become dominated by endophyte-infected plants over time. In some cases rapid increases in endophyte infection can occur within $1-3$ years after pasture is sown (Prestidge et al. 1984; Prestidge et al. 1985; Popay et al. 1999; Thom et al. 1999). Such a rapid change must arise from infected seed, which may have been shed within the pasture prior to sowing or been brought in via animal dung (van Vught and Thom 1997). However, the endophyte-free resident pasture is also likely to be shedding seed, suggesting that the infected seed is more successful than the endophyte-free seed in establishing new plants.

In this paper we report on four trials that compared the disappearance of endophyte-infected and endophyte-free seed and newly germinated seedlings. We included clover seed in one trial and seed infected with either a wild-type endophyte which occurs naturally in New Zealand or a novel endophyte, AR1, in two trials. Seed feeding preferences of black field cricket (Teleogryllus commodus), a small native field cricket (Pteronomobius spp.) and black beetle were also investigated.

\section{Trial 1, April 1998}

\section{METHODS}

The trial was conducted within an area of endophyte-free perennial ryegrass, $\mathrm{cv}$. Yatsyn 1, on a Te Kowhai clay loam soil at the Dairying Research Corporation Farm, No. 5 Dairy near Hamilton. Wire quadrats, $100 \times 100 \mathrm{~mm}$, were placed about $100 \mathrm{~mm}$ apart in groups of three on areas of bare soil within the sward. Any grass litter or other debris was removed prior to placement of the quadrats. Each quadrat of a group was 
randomly allocated to one of three treatments: Nui perennial ryegrass without endophyte (EF) or with the wild-type endophyte (WT), or Huia white clover (CL) seed. Within each quadrat two parallel grooves, about $10 \mathrm{~mm}$ deep, were carved into the soil and 5 seeds were placed in each groove. Seed was left uncovered. There were 10 replicated groups of quadrats placed randomly within the sward. Five of these replicates were randomly selected and covered with bird netting placed over a wire frame and fastened to the ground with wire pegs. The remaining five replicates were left uncovered.

The trial commenced on 7 April and every 2-4 days from then until 28 April, the number of seeds remaining in each quadrat was recorded and the germination status of each was noted. On three occasions in May the number of seedlings present in each quadrat was counted, with a final count made on 20 May, 39 days after seed placement.

\section{Trial 2, April 1999}

This trial was carried out on the same area as Trial 1 and, using the same methodology, compared the disappearance of Nui ryegrass seed infected with the wild-type endophyte and endophyte-free seed. There were seven replicates and within each replicate there were both covered and uncovered quadrats. The trial commenced on 1 April and seed numbers were recorded on four occasions between then and 24 April when the trial was terminated.

\section{Trial 3, March/April 2000}

This trial was located on a humic silt loam soil at the Ruakura Research Station, Hamilton. Treatments were Nui perennial ryegrass EF seed and seed infected with WT or a novel endophyte (AR1). Treatments were randomly assigned to each group of three quadrats, with 10 replicates of each treatment. Seeds were placed in each quadrat as described above and each quadrat was covered with a wire milk crate.

The trial started on 23 March and was monitored for 28 days. Number of seed and their germination status was recorded as before. On Day 28 all ungerminated seed was collected and checked under a microscope for insect damage. Undamaged seed was placed on damp filter paper in a Petri dish for 1 week to check for viability as described below.

Germination of 50 seeds of each treatment used in the trial was tested over 1 week by placing them on damp filter paper in Petri dishes in the dark at $20^{\circ} \mathrm{C}$. Endophyte infection was determined on 30 seeds from each treatment by staining and microscopic examination of seed tissue.

\section{Trial 4, April 2000}

This trial was carried out on clay loam soil at the Ruakura Research Station. The methods used were the same as for Trial 3 except that the trial commenced on 29 March.

\section{Insect Trials}

Choice and no choice tests were conducted with black field cricket (BFC) nymphs and adults, small field cricket (SFC) adults and black beetle (BB) adults to determine how readily they consumed ryegrass seed and whether they showed any preference for endophyte-free compared with endophyte-infected seed. The trial with BFC nymphs also included white clover and was conducted with both ungerminated and germinated seed. Consumption of germinated seed by BB adults was also investigated. All tests used field-collected insects and were conducted in the laboratory at ambient temperatures $\left(15-25^{\circ} \mathrm{C}\right)$. Germinated seed was obtained by leaving seed on damp filter paper in the dark at $20^{\circ} \mathrm{C}$. Tests were conducted between 5 and 10 days after seeds were set up for germination.

Black field cricket. For a choice test with BFC nymphs (average weight $17.5 \mathrm{mg}$ ), plastic dividers radiating from a central washer were placed inside Petri dishes lined with damp filter paper. This divided each Petri dish into six compartments that could be accessed by an insect through the centre. Each compartment was randomly assigned to one of six treatments: five ungerminated or germinated seeds of $\mathrm{CL}, \mathrm{EF}$ or WT ryegrass. There were 18 replicate dishes with a single cricket nymph placed in each dish on 10 March 1998. The number of damaged or eaten seeds was recorded daily for the next 3 days. 
For the choice test with adult BFC, small plastic containers ( $30 \mathrm{ml}$ capacity) each containing 10 seeds of each treatment, EF, WT or AR1 ryegrass, were placed adjacent to each other on a layer of sand in the bottom of a larger plastic container. A single fieldcollected adult cricket was placed inside the larger container, which was then covered loosely with a lid. There were 20 replicates. The number of undamaged seed was recorded after $24 \mathrm{~h}$. All remaining seed was then removed and a further 10 seeds were placed in each small container. Damage to these seeds was checked after $24 \mathrm{~h}$.

In the no-choice test with adult BFC, 10 replicates with 20 seeds of each of the same treatments used in the choice test were placed in $90 \mathrm{~mm}$ diameter Petri dishes and one adult black field cricket was placed inside each dish. The number of undamaged seeds remaining after $24 \mathrm{~h}$ was determined, and then fresh seed was put into each dish. This was checked for damage after a further $24 \mathrm{~h}$.

Small field cricket. Choice and no-choice tests were conducted as described above for the adult BFC on SFC collected from pasture at Ruakura Research Centre. There were 10 replicates of each treatment for both tests. Damage to seed was checked after $48 \mathrm{~h}$.

In addition, for each treatment eight germinated seeds were placed on damp filter paper in a $90 \mathrm{~mm}$ Petri dish with two crickets and replicated five times. Crickets were removed after $24 \mathrm{~h}$ and the number of damaged seedlings recorded.

Black beetle adults. Choice tests were carried out in partitioned Petri dishes as described above for BFC nymphs. Five Nui ryegrass seeds of the three treatments, EF, WT or AR1, were each randomly assigned to two compartments of each Petri dish and one BB adult placed in the centre of the dish on 23 March 2000. The dishes were covered with lids, placed together in stacks of three, and held together with rubber bands. Seeds were counted after $24 \mathrm{~h}$. Seeds were left in the petri dishes to germinate, and the beetles additionally supplied with a small piece of carrot. On 3 April the seedlings in each compartment were counted and examined for damage. The carrot was then removed from all dishes and a week later all seedlings were counted and examined again. Seedlings were removed and replaced with a single fresh seedling in each compartment in replicates 1-10. These were checked for feeding damage after a further $24 \mathrm{~h}$.

Analysis

At each check date for all field seed trials the number of seed remaining in each treatment was compared by analysis of variance. Cover was tested as a factor in Trials 1 and 2. Untransformed data from the insect feeding trials were also subjected to analysis of variance.

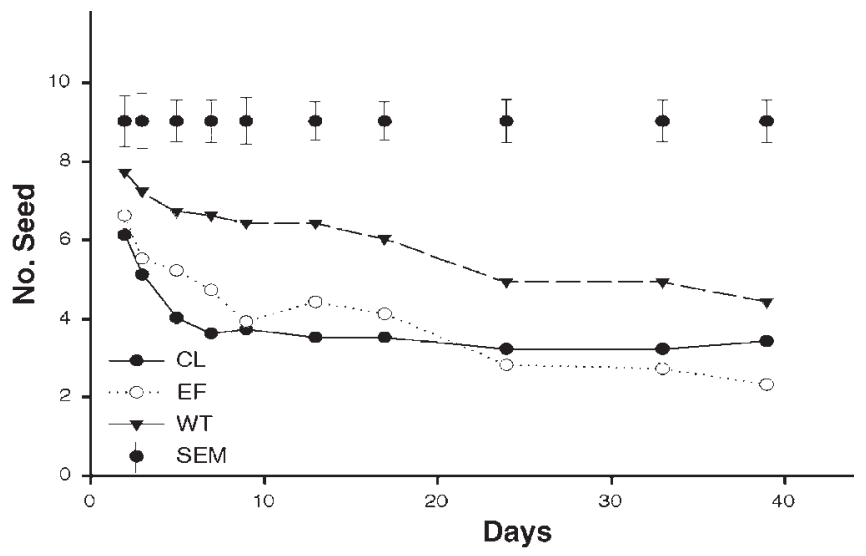

FIGURE 1: Seed disappearance of endophyte-free (EF) ryegrass seed, ryegrass seed infected with a wild-type endophyte (WT) and clover seed (CL) in Trial 1. 


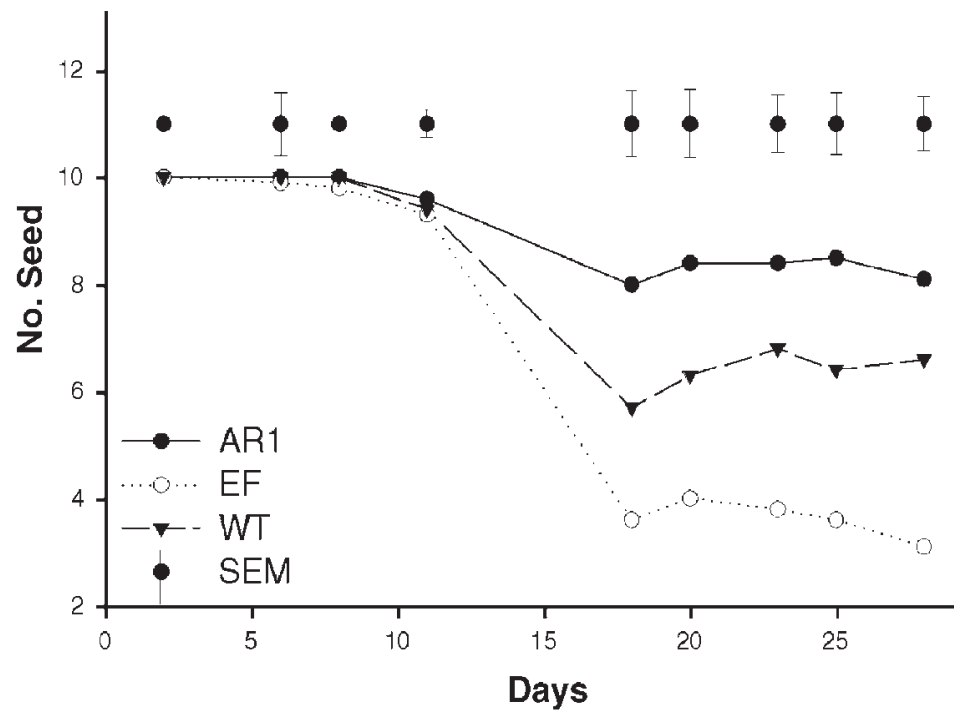

FIGURE 2: Disappearance of endophyte-free (EF) ryegrass seed and ryegrass seed infected with a wild-type endophyte (WT) or a novel endophyte (AR1) in Trial 3.

\section{Trial 1, April 1998}

\section{RESULTS}

Uncovered seed had a higher rate of disappearance than covered seed (Table 1) but the difference in the number of seeds in covered and uncovered treatments was only significant $(\mathrm{P}<0.05)$ on the fifth day after the trial began. There were no interactions between seed type and cover. The disappearance of CL and EF seed was similar for the duration of the trial whereas endophyte infection of the ryegrass seed reduced seed disappearance from Day 5 ( $\mathrm{P}<0.01$ ) (Fig. 1). Between Day 5 and Day $10 \mathrm{EF}$ and $\mathrm{CL}$ seed disappeared at a faster rate than did WT seed but thereafter the disappearance rate was similar for all treatments. Total number of WT seed remained significantly higher than the $C L$ and EF seed $(P<0.01)$ until Day 17 . From Day 24 , when only germinated seeds were counted, there were fewer EF than WT seedlings $(\mathrm{P}<0.05)$ until the trial ended on Day 39. By this time, $44 \%$ of the WT seeds set down at the beginning of the trial had survived as seedlings compared with $23 \%$ of the EF seeds and $34 \%$ of the CL seeds.

\section{Trial 2, April 1999}

As for Trial 1, fewer EF and WT seeds were found in uncovered quadrats compared with covered quadrats but at no time were the differences significant $(\mathrm{P}>0.05)$ (Table 1). There were no interactions between cover and endophyte infection. Endophyte infection did not reduce total seed disappearance during the trial $(\mathrm{P}>0.05)$ but on Day 22 when the trial was terminated there were more germinated WT seeds present than EF seeds $(\mathrm{P}<0.05)$ (Table 1$)$.

\section{Trial 3, March/April 2000}

Few seeds of any treatment disappeared for the first 11 days of this trial but by Day 18 there were fewer EF seeds found than WT or AR1 seeds $(\mathrm{P}<0.01)$, and also fewer WT seeds than AR1 seeds $(\mathrm{P}<0.05)$ (Fig. 2). Although these relative differences continued through to the end of the trial, the differences between the number of WT and AR1 seed were not significant at Day 23 and Day 28. In addition to total seed disappearance, the survival of seed to germination was lower in the EF treatment than in the WT or AR 1 treatments. Of the 100 seeds used, four ungerminated AR 1 and five WT seeds were recovered on Day 28 whereas the number of ungerminated EF seeds 
was 27 . As a result the survival to seedlings after 4 weeks was $75 \%$ for AR $1,59 \%$ for WT and $7 \%$ for EF. Only $33 \%$ of the ungerminated EF seeds showed signs of insect feeding damage but the remainder also failed to germinate. When tested in the laboratory, percent germination was $98 \%, 90 \%$ and $86 \%$ respectively for the AR1, WT and EF seed used in the trial. Endophyte infection rates of the seed were $85 \%$ for $\mathrm{AR} 1,81 \%$ for $\mathrm{WT}$ and $0 \%$ for $\mathrm{EF}$.

\section{Trial 4, April 2000}

The pattern of seed disappearance in this trial was similar to that in Trial 3, with a large seed loss occurring in all treatments between Day 5 and Day 12 (equivalent to Day 11 and Day 18 in Trial 3). Again seed recovery was higher in the AR1 and WT treatments than the EF treatment ( $>90 \%$ in all treatments on Day 5 declining to $18 \%$ on Day 12 for EF, compared with $37 \%$ for AR1 and 38\% for WT) (Table 2), but these differences were not significant. There was little disappearance of seed after this time and the number of seeds which had germinated by Day 22 was similar to the total seed found on Day 12 (Table 2). Only 1 ungerminated seed was recovered (an AR1 seed) at the end of the trial.

TABLE 1: Mean number of seeds/quadrat in covered and uncovered treatments of Trials 1 and 2, and of endophyte-free ryegrass or endophyteinfected (wild-type) ryegrass in Trial 2 at different times after field placement.

\begin{tabular}{lcccc}
\hline Treatment & \multicolumn{4}{c}{ Days after seeding } \\
& Day 2 & Day 5 & Day 9 & Day $17^{1}$ \\
\hline Trial 1 & & & & \\
Covered & 6.9 & $6.2 *$ & 5.2 & 4.6 \\
Uncovered & 6.7 & 4.4 & 4.1 & 2.6 \\
$\quad$ SED & 0.89 & 0.75 & 0.82 & 0.69 \\
Trial 2 & Day 7 & Day 9 & Day 14 & Day $22^{1}$ \\
Covered & 7.2 & 5.7 & 5.1 & 3.0 \\
Uncovered & 6.7 & 4.5 & 4.1 & 3.1 \\
Wild-type & 6.7 & 5.1 & 4.6 & 3.7 \\
Endophyte-free & 7.2 & 5.2 & 4.6 & 2.4 \\
$\quad$ SED & 1.05 & 0.80 & 0.71 & 0.77 \\
\hline
\end{tabular}

${ }^{1}$ Germinated seeds only.

*Indicates a significant difference $(\mathrm{P}<0.05)$ between a treatment pair.

TABLE 2: Mean number of seeds/quadrat of endophyte-free ryegrass and ryegrass infected with a novel endophyte (AR1) or a wild-type endophyte found at different intervals after field placement in Trial 4.

\begin{tabular}{lccccc}
\hline Treatment & Day 2 & Day 5 & Days 12 & Day 17 & Day 22 \\
\hline AR1 & 9.2 & 9.3 & 3.7 & 3.2 & 3.0 \\
Wild-type & 9.3 & 9.1 & 3.8 & 3.0 & 3.1 \\
Endophyte-free & 9.9 & 9.4 & 1.8 & 1.9 & 1.7 \\
$\quad$ SED & 0.48 & 0.49 & 1.19 & 0.83 & 0.88
\end{tabular}

${ }^{1}$ Germinated seeds only.

\section{Insects}

BFC nymphs readily consumed ungerminated clover seed but not perennial ryegrass seed $(\mathrm{P}<0.01)$, but damaged more germinated ryegrass seed than clover seed $(\mathrm{P}<0.01)$ (Table 3). The nymphs damaged as many endophyte-infected ryegrass seeds as endophyte-free. 
Adult BFC readily consumed ryegrass seed but showed no aversion to endophyte infection (Table 3). In the no-choice test the adults damaged more WT-infected seed than EF or AR1 seed and this difference was significant for the second test $(\mathrm{P}<0.01)$ (Table 3). No preferences were apparent in the choice test.

Like BFC nymphs, native crickets did not readily eat ryegrass seed (no seed damaged after $24 \mathrm{~h}$ ) but damaged germinated seed (Table 3 ). The number of damaged seeds was similar for all treatments. Black beetle adults did not damage ryegrass seed or any of the seedlings used in these tests but have been observed to eat small quantities of seed in other trials (J. Baltus, unpubl. data).

Table 3: Mean number of clover seeds, and ryegrass seeds without endophyte (EF), with a wild-type endophyte (WT) or with a novel endophyte (AR1) damaged by black field cricket (BFC) nymphs and adults and native cricket adults.

\begin{tabular}{|c|c|c|c|c|c|c|c|c|c|c|}
\hline \multirow[b]{2}{*}{ Insect } & & \multirow[b]{2}{*}{$\mathrm{n}^{1}$} & \multicolumn{2}{|c|}{ Clover } & \multicolumn{2}{|c|}{$\mathrm{EF}$} & \multicolumn{2}{|c|}{ WT } & \multirow{2}{*}{$\begin{array}{c}\text { AR1 } \\
\text { NG }\end{array}$} & \multirow[t]{2}{*}{ SED } \\
\hline & & & $\mathrm{G}^{2}$ & $\mathrm{NG}$ & $\mathrm{G}$ & $\mathrm{NG}$ & G & $\mathrm{NG}$ & & \\
\hline $\mathrm{BFC}$ & C & 5 & 2 & 1.9 & 3.4 & 0.1 & 3.3 & 0.2 & - & 0.37 \\
\hline BFC Adult & Choice $^{3}$ & 10 & - & - & - & 7.1 & - & 7.9 & 7.9 & 0.65 \\
\hline BFC Adult & No choice ${ }^{3}$ & 20 & - & - & - & 9.0 & - & 18.0 & 8.8 & 2.97 \\
\hline Small cricket & No choice - $\mathrm{G}$ & 8 & - & - & 6.4 & - & 6.4 & - & 5.4 & 1.17 \\
\hline
\end{tabular}

${ }^{1}$ Number of seeds per replicate.

${ }^{2} \mathrm{NG}$ - Ungerminated seeds; G - Germinated seeds.

${ }^{3}$ Means are for second test.

\section{DISCUSSION}

Although the effect of Neotyphodium endophytes in perennial ryegrass and tall fescue plants on invertebrate herbivory has been well documented, there is little information on the consequences of infection in seed. In the trials described here seed disappearance was clearly reduced by endophyte presence, but we were unable to ascertain the reasons for this. Covering seed in Trials 1 and 2 reduced the disappearance rate but in most cases this was not a significant effect and no endophyte by cover interactions were demonstrated. Furthermore in Trials 3 and 4, in which all seed was covered, $69 \%$ and $82 \%$, respectively, of the endophyte-free seed disappeared. Although Madej and Clay (1991) showed that birds distinguished between infected and endophyte-free seed of tall fescue, in our trials birds appear to have neither removed a lot of seed nor shown any preference for endophyte-free ryegrass seed. Of the insects tested, only adult black field cricket readily consumed seed but this insect ate as many, and in one case more, endophyte-infected than endophyte-free seed. There was also no evidence that damage to germinating seed was resulting in its disappearance. Had damage occurred to the developing shoot the remainder of the seed would most likely still be present. Furthermore the BFC nymphs and native crickets, which were abundant in the trial areas and which damage developing seedlings, did not discriminate on the basis of endophyte infection.

Other possible seed feeders in the pasture environment include earthworms and mice. Mice appear to show no preference for endophyte-free ryegrass seed over endophyte-infected (Varney et al. 1989), but the sensitivity of earthworms to endophyte is not known. A considerable amount of earthworm activity was noted in or near the quadrats in Trials 1,2 and 4 but much less in Trial 3 where the most dramatic differences between endophyte-free and endophyte-infected seed were recorded. In Trial 3, although seed disappearance was the main factor in only $4 \%$ of the EF seed establishing as seedlings, poor germination of this seed was also a contributing factor. This effect on germination was not apparent in Trial 4 for which the same seed was used, or in the germination tests conducted under laboratory conditions. Exposure to sunlight and high temperatures on the bare ground for nearly two weeks prior to 
germination may have affected the EF more than the AR1 and WT seed, which had been more recently harvested.

It is possible that absorption of moisture by the seed during the germination process influenced seed disappearance. In Trial 1 rain fell within the first three days of seed placement and it was during this period and the following 4 days that most of the seed disappeared in this trial. In contrast to this, for the first $1-2$ weeks in Trials 3 and 4 there was little seed disappearance and most of the seed vanished during a week in which rain initiated germination.

Ryegrass seed infected with the WT endophyte contains high concentrations of the known insect-active alkaloids, peramine and lolitrem B (Ball et al. 1993) and ergovaline (Rottinghaus et al. 1991). Even when the endophyte is no longer viable in the seed the alkaloids remain at high levels (Ball et al. 1993) and will protect young seedlings from insect attack (Stewart 1985). The novel endophyte, AR1, does not produce lolitrem B or ergovaline but does produce peramine. The high survival of AR1, particularly in Trial 3, does not necessarily mean that peramine is a major factor in reducing seed disappearance. Other evidence indicates that other, as yet unidentified, insect-active factors are produced by this endophyte (Popay et al. 1999).

The contribution that natural reseeding makes to pasture plant population dynamics is difficult to estimate. In a dry hill country study cumulative small annual inputs from reseeding was estimated to contribute $31 \%$ of the ryegrass tillers present (Hume and Barker 1991; Hume 1999). If this level of reseeding is common then factors such as selective seed predation may be a significant modifying influence on pasture composition over time. Our results certainly show that there is a lower success rate for the establishment of ryegrass plants from endophyte-free seed compared with endophyte-infected. Further research is needed however, to identify the agent of the seed disappearance observed in our trials.

\section{ACKNOWLEDGEMENTS}

Errol Thom, Dairying Research Corporation, Hamilton, for helpful discussion and provision of the trial site in 1998 and 1999. This research was funded by the Foundation for Research, Science and Technology.

\section{REFERENCES}

Ball, O.J-P. and Prestidge, R.A., 1992. The effect of the endophytic fungusAcremonium lolii on adult black beetle (Heteronychus arator) feeding. Proc. 45th N.Z. Plant Prot. Conf: : 201-204.

Ball O.J-P., Prestidge, R.A. and Sprosen, J.M., 1993. Effect of plant age and endophyte viability on peramine and lolitrem B concentration in perennial ryegrass seedlings. Pp 63-66 In: Proc. 2nd Int. Symp. on Acremonium/ Grass Interactions, D.E. Hume, G.C.M. Latch and H.S. Easton (Eds); Palmerston North, New Zealand.

Hume, D.E., 1999. Establishing and maintaining a toxin-free pasture: a review. In: Ryegrass Endophyte: An Essential New Zealand Symbiosis, Grassland Research and Practice Series No. 7: 123-132.

Hume, D.E. and Barker, D.J., 1991. Natural reseeding of five grass species in summer dry hill country. Proc. N.Z. Grassland Assoc. 53:97-104.

Madej, C.W. and Clay, K., 1991. Avian seed preference and weight loss experiments: the effect of fungal endophyte-infected tall fescue seeds. Oecologia 88: 296-302.

Popay, A.J., Hume, D.E., Baltus, J.G., Latch, G.C.M., Tapper, B.A., Lyons, T.B., Cooper, B.M., Pennell, C.G., Eerens, J.P.J. and Marshall, S.L. 1999. Field performance of perennial ryegrass (Lolium perenne) infected with toxin-free fungal endophyte (Neotyphodium spp.). In: Ryegrass Endophyte: An Essential New Zealand Symbiosis, Grassland Research and Practice Series No. 7: 113122.

Prestidge, R.A., Pottinger, R.P. and Barker, G.M. 1982. An association of Lolium endophyte with ryegrass resistance to Argentine stem weevil. Proc. 35th N.Z. Weed and Pest Control Conf.: $119-122$. 
Prestidge, R.A., Van der Zijpp, S. and Badan, D., 1984. Effects of Argentine stem weevil on pastures in the Central Volcanic Plateau. N.Z. J. Expt. Agric. 12: 32331.

Prestidge, R.A., di Menna, M.E., van der Zjipp, S. and Badan, D., 1985. Ryegrass content, Acremonium endophyte and Argentine stem weevil in pastures in the volcanic plateau. Proc. 38th N.Z. Weed and Pest Control Conf.: 41-44.

Rottinghaus, G.E., Garner, G.B., Cornell, C.N. and Ellis, J.L., 1991. HPLC method of quantitating ergovaline in endophyte-infected tall fescue: seasonal variation in ergovaline levels in stems with leaf sheaths, leaf blades and seedheads. J. Agric. and Food Chem. 39: 112-115.

Stewart, A.V., 1985. Perennial ryegrass seedling resistance to Argentine stem weevil. N.Z. J. Agric. Res. 28: 403-407.

Thom, E.R., Clark, D.A. and Waugh, C.D., 1999. Growth, persistence and alkaloid levels of endophyte-infected and endophyte-free ryegrass pastures grazed by dairy cows in northern New Zealand. N.Z. J. Agric. Res. 42: 241-253.

Van Vught, V.T. and Thom, E.R., 1997. Ryegrass contamination of endophyte-free dairy pastures after spray-drilling in autumn. Proc. N.Z. Grassl. Assoc. 59:233237.

Varney, D.R., Prestidge, R.A., Jones, D.D., Varney, L.A., Zavos, P.M. and Siegel, M.R., 1989. Effect of endophyte-infected perennial ryegrass seed diets on growth and reproduction in mice. N.Z. J. Agric. Res. 32: 547-554. 